\title{
CIRCUITOS EDUCATIVOS: A ESCOLA MODERNA N. 1 E OS GINÁSIOS VOCACIONAIS NOTURNOS, UM ESTUDO COMPARATIVO 12
}

\author{
Carmen Sylvia Vidigal Moraes (FEUSP-Brasil) ${ }^{3}$ \\ Doris Accioly e Silva (FEUSP - Brasil) ${ }^{4}$
}

\begin{abstract}
Resumo
O trabalho apresenta resultados iniciais de projeto de pesquisa mais amplo sobre práticas culturais e educativas desenvolvidas pelo movimento operário ou direcionadas aos trabalhadores pelos setores dominantes no decorrer do século $X X$, especificamente no estado de São Paulo. É nosso objetivo específico localizar/destacar o percurso do ideário anarquista, traduzido num conjunto de prescrições práticas para a organização da denominada Escola Moderna n.1 por grupos anarquistas, entre 1912 e 1919, tomado comparativamente ao projeto pedagógico dos Ginásios Vocacionais Noturnos, uma iniciativa de política pública de educação, nos anos 1960, destinada a jovens e adultos trabalhadores.
\end{abstract}

Palavras chave: educação libertária, ginásio vocacional, educação e trabalho.

\section{Resumen}

El trabajo presenta resultados iniciales de proyecto de investigación más amplio sobre prácticas culturales y educativas desarrolladas por el movimiento obrero 0 dirigidas a los trabajadores por los sectores dominantes a lo largo del siglo XX, específicamente en el estado de São Paulo. Es nuestro objetivo específico localizar / destacar el recorrido del ideario anarquista, traducido en un conjunto de prescripciones prácticas para la organización de la denominada Escuela Moderna n. 1 por grupos anarquistas, entre 1912 y 1919, tomado comparativamente al proyecto pedagógico de los Institutos Vocacionales Nocturnos, una iniciativa de política pública de educación, en los años 1960, destinada a jóvenes y adultos trabajadores.

Palabras clave: educación libertaria, gimnasio vocacional, educación y trabajo.

\footnotetext{
${ }^{1}$ DOI: https://doi.org/10.22409/tn.16i29.p4554

${ }^{2}$ A temática, aqui desenvolvida, constituiu um dos tópicos do programa do Minicurso "Educação socialista e emancipação social: concepções e experiências ao longo do século XX", ministrado na 38 $8^{\text {a }}$ Reunião Nacional da ANPEd - 01 a 05 de outubro de 2017 - UFMA - São Luís/MA. Com algumas modificações, o texto baseia-se no trabalho apresentado em VII Jornadas Científicas de la SEPHE e V Simposio Iberocamericano: Historia, Educación, Patrimonio Educativo, realizado em San Sebastian, País Basco, entre os dias 29 de junho e 1 de julho de 2016, e publicado nos Anais do Colóquio.

3 Professora livre-docente da Faculdade de Educação -USP. moraescs@usp.br

${ }^{4}$ Professora doutora da Faculdade de Educação -USP . daccioly@usp.br
} 


\section{Introdução}

O propósito do artigo consiste em apresentar as considerações iniciais de projeto de pesquisa mais amplo sobre práticas culturais e educativas desenvolvidas pelo movimento operário ou direcionadas aos trabalhadores pelos setores dominantes no decorrer do século XX, especificamente no estado de São Paulo, uma das regiões do Brasil em que tais iniciativas se manifestam com maior força e onde a documentação historiográfica apresenta-se mais rica.

É nosso objetivo específico localizar/destacar o percurso do ideário anarquista, a influência produzida por este ideário relativamente às ações educativas, traduzida num conjunto de prescrições práticas para a organização da denominada Escola Moderna n. 1 por grupos anarquistas (no caso anarcosindicalistas) entre 1912 e 1919, tomando-o comparativamente ao projeto pedagógico dos Ginásios Vocacionais Noturnos, uma iniciativa de política pública de educação, nos anos 1960, destinada a jovens e adultos trabalhadores. Experiência pedagógica diferenciada e de caráter emancipatório, extinta pelo governo civil militar (1964 - 1985), opunha-se à estrutura dual do ensino médio, concebia a formação geral integrada à formação para o trabalho, não dissociava educação e cultura e, tampouco, educação e trabalho.

A construção do inventário dessas duas propostas educacionais que se contrapunham aos modelos hegemônicos de escolarização pretende possibilitar a discussão das formas de apropriação de estratégias educativas que circulavam na sociedade brasileira, tanto no âmbito dos governos quanto no de grupos de trabalhadores, no movimento operário e sindical, contribuindo para restituir à história educacional do período a dimensão das disputas em torno de projetos pedagógicos diferenciados e a mobilização de dispositivos que serviram a uma pluralidade de propósitos distintos e/ou antagônicos.

Com essa perspectiva de análise, pretende-se evitar um equívoco recorrente na historiografia brasileira, o da visão demiúrgica do Estado, do Estado onipotente e onipresente, que antecipa as classes para poder criá-las e promover o capitalismo tardio (CHAUÍ, 1978, HARDMAN, 1983). Nesse esquema empobrecido, a luta de classes não é constituinte do processo histórico, mas apenas o seu resultado, uma vez que nenhuma das classes em presença, nenhuma das frações de classe apresentaria os requisitos para elaborar projetos

TrabalhoNecessário- www.uff.br/revistatrabalhonecessario: ano 16, №29/2018 
próprios e apropriar-se do poder, vazio preenchido pelo poder do Estado. No que diz respeito à historiografia educacional no período estudado queremos evitar igualmente outro equívoco: era dominante o recurso à figura do transplante cultural como um lugar-comum, que explicava o abismo alegado entre os bons propósitos ilustrados de uma elite convencida do poder democratizador e liberalizador da educação e os resultados efetivos desses propósitos. Os projetos educacionais dessas ilustres elites não se teriam transformado em realidade porque inspirados em ideologia forjada no estrangeiro, como entende, por exemplo, G. Bastos Silva (1983).

Uma questão paralela e importante neste trabalho de pesquisa consiste em demarcar que, no domínio de investigação dirigido à história das relações entre trabalho e educação, os esforços relativos aos procedimentos de método procuram, em primeiro lugar, superar análises que reduzem o seu objeto de estudo - o das relações entre as duas esferas da atividade social - a dois termos pensados separadamente: educação e divisão do trabalho, escola e empresa, ou ensino geral e ensino profissional. Entende-se que apenas a análise histórica possibilita superar equívocos presentes em abordagens que apreendem isoladamente estas categorias. A compreensão da realidade social, que se enraíza necessariamente no passado e se projeta no futuro, consiste em exigências de conhecimento e inteligibilidade que permitem objetivar situações concretas, singulares.

Com essas preocupações e a partir de fontes primárias (fontes documentais textuais, aliadas às iconográficas e complementadas pelas fontes orais) e secundárias pretende-se contribuir para alargar a compreensão da dimensão política destas escolas, contextualizando-as; indicar as suas especificidades relativas à renovação metodológica que empreenderam no campo pedagógico; analisar interfaces possíveis em suas práticas e concepções; e, por fim, apresentar contribuições para o repensar do ensino público na atualidade brasileira. 


\section{O resgate da Memória: reconstruindo a história por meio de fontes primárias e secundárias.}

Como já foi explicitado, a comunicação baseia-se em dois trabalhos de pesquisa histórica e arquivística ${ }^{4}$, realizados por grupo de pesquisadores, professores e alunos bolsistas (Iniciação Científica, Mestrado e Doutorado) do Centro de Memória de Educação, da Faculdade de Educação, da Universidade de São Paulo/Brasil, os quais consistem no recolhimento, organização, acondicionamento e referenciação das fontes de dois Acervos que se encontram, hoje, sob a guarda daquele Centro de Memória da Educação/CME: o Acervo João Penteado e o Acervo Maria Nilde Mascelani, este último ainda em processo de organização e análise.

O Arquivo Escolar João Penteado consiste em conjunto documental inédito, de interesse substantivo para a reconstrução histórica das práticas educativas, composto de documentos produzidos e acumulados por uma das organizações escolares criadas e mantidas por anarquistas no país, a Escola Moderna №. 1, e pelas posteriores instituições educacionais que funcionaram a cargo do educador João Penteado (1912 a 1961), bem como o seu Arquivo Pessoal, que incluem documentos escritos pelo professor, os quais expressam com relevante ineditismo o pensamento deste importante militante da educação libertária no Brasil.

É bastante conhecida a importância atribuída à educação pelo movimento anarquista, vinculada intimamente à concepção de "revolução social" que defendiam, ao processo de consolidação da ordem social libertária que pretendiam instaurar (LUIZETTO, 1987). É possível observar, nesse sentido, entre as diversas iniciativas culturais de natureza pedagógica (imprensa, teatro, literatura etc), a criação e a manutenção de escolas, centros de estudos e universidades populares. No entanto, apesar do esforço de alguns

\footnotetext{
${ }^{4}$ Projeto "Pesquisa sobre Educação e Cultura Anarquistas em São Paulo: o Arquivo João Penteado", realizado pelo grupo interdisciplinar de estudos e pesquisas sobre Cultura e Educação Anarquistas, financiado com auxílio do CNPq e FAPESP. Finalizado em 2012, produziu o livro "Educação Libertária no Brasil", publicado em 2014 (EDUSP e FAP-Unifesp), contendo o Inventário de Fontes do Acervo João Penteado e análises sobre os documentos levantados. E o Projeto "O Ensino Renovado em São Paulo: Classes Experimentais, Ginásios Vocacionais e Escolas de Aplicação (1950-1970)", em andamento no CME-FEUSP, com a participação dos professores Carmen S.V. Moraes-FEUSP (coord.), Angela de Barros Tamberlini-UFF e Doris Accioly e Silva-FEUSP.
}

TrabalhoNecessário- www.uff.br/revistatrabalhonecessario: ano 16, №29/2018 
pesquisadores $^{5}$, no âmbito das atividades educacionais desenvolvidas pelo anarquismo no Estado de São Paulo, as práticas relacionadas à educação escolar permanecem as menos conhecidas. Em grande parte, como observa Luizetto (1987), os problemas têm residido nas lacunas de informação causadas pela ausência de fontes e/ou dificuldade de se reunir séries documentais completas. A esse respeito, entende-se que 0 acesso a documentos inéditos dos arquivos das escolas dirigidas por João Penteado, no largo período de quase 50 anos, pode propiciar a abertura de novas perspectivas de conhecimento a respeito das práticas educacionais libertárias propostas e implementadas pela Escola Moderna, bem como sobre a história do ensino no estado.

O acervo, doado por parentes de João Penteado6, possui cerca de 37.610 documentos administrativos e pedagógicos; 900 fotografias soltas e 24 Álbuns de formaturas e outros eventos escolares, num total de 4800 fotos; filme sobre eventos comemorativos e atividades esportivas; 300 exemplares dos jornais elaborados por professores e alunos; 200 manuscritos do fundador; e cerca de 167 peças museológicas, como quadros, objetos do antigo Laboratório para o ensino de ciências, da geografia, maquinário das aulas de datilografia, projetor de imagens de $16 \mathrm{~mm}$, entre outros, além de móveis utilizados na escola, como estantes e carteiras. Algumas peças contêm identificação de sua procedência ou ano de fabricação, indicando as marcas Bender (BRA), Burroughs (USA), Waller (BRA), Remington (BRA), entre outras.

O Arquivo constitui-se de séries documentais completas acumuladas no estabelecimento de ensino ao longo de quase 50 anos, entre 1912 e 1961, contendo informações relevantes sobre a vida institucional nos diferentes momentos de sua história nos quais esteve sob a direção do referido educador anarquista: Escola Moderna n. 1 (1912 - 1919); Escola Nova (1920 - 1923): Academia de Comércio Saldanha Marinho (1924 - 1943); Escola Técnica de Comércio Saldanha Marinho (1944 - 1947); Ginásio e Escola Técnica Saldanha Marinho (1948 - 1961). A denominação e cronologia das escolas, criadas pelo educador após a extinção da Escola Moderna, estão relacionadas não apenas às suas atribuições pedagógicas, aos níveis e modalidades de cursos ofertados, mas

\footnotetext{
${ }^{5}$ Entre esses pesquisadores, podem ser citados Flávio Luizetto (1984, 1986, 1987,), Edgar Rodrigues (1992), Silvio Gallo (1995).

${ }^{6}$ A esse respeito, consultar Moraes, Carmen S.V. (org.), 2012.
}

TrabalhoNecessário- www.uff.br/revistatrabalhonecessario: ano 16, №29/2018 
também à necessidade de obedecer a denominações e regras prescritas pelas normas legais, frequentemente modificadas pelos governos estadual e federal ${ }^{7}$.

O Arquivo Pessoal, organizado separadamente, reúne 751 documentos: fotografias, correspondências e produção intelectual de João Penteado (livros, peças de teatro, poemas, discursos, textos didáticos). O Centro de Memória da Educação tem sob sua guarda parte da biblioteca escolar que estava alocada no prédio do Colégio Saldanha Marinho, constituída por 120 volumes, 14 periódicos, e 03 apostilas elaboradas na escola. Essa parte da biblioteca inclui obras pedagógicas, de conteúdo didático, técnico - voltado ao ensino comercial e da contabilidade, e outras relacionadas ao campo do espiritualismo, principalmente ao espiritismo kardecista e ao espiritualismo de krishnamurti.

As propostas educacionais libertárias chegaram ao Brasil, trazidas pelo movimento anarquista já no final do século XIX. A partir dos anos 1890 , as concepções socialistas e anarquistas difundem-se com a expansão urbana e industrial, o aumento do fluxo imigratório e o consequente aumento no número de trabalhadores e operários. Entre as ações educacionais desenvolvidas pelos militantes e simpatizantes anarquistas encontra-se a abertura de várias escolas no Estado de São Paulo, duas delas na capital, as chamadas Modernas, situadas nos bairros operários do Belenzinho e do Brás, e dirigidas, respectivamente, por João Penteado e Adelino Pinho. O primeiro passo foi a constituição de um Comitê organizador da Escola Moderna de São Paulo, em 1909, encarregado de programar a Escola Moderna n.1 e providenciar os recursos econômicos indispensáveis ${ }^{8}$. Em 1912, após obter autorização do Diretor Geral da Instrução

\footnotetext{
${ }^{7}$ Ao mesmo tempo, não deixa de despertar interesse a escolha dos nomes que the foram atribuídos, seja o de Escola Nova, referência provável ao expressivo movimento pedagógico em curso no país, na época; seja o de Saldanha Marinho, que homenageia importante 'republicano histórico' de São Paulo, dos momentos da Propaganda, e o primeiro Grão mestre da Maçonaria Republicana, eleito por voto secreto pelos maçons, em oposição à ala maçônica que apoiava o Governo Imperial, liderada pelo Visconde do Rio Branco (Moraes, 2006).

${ }^{8}$ Conforme observa Edgar Rodrigues (1992), inúmeras outras iniciativas ocorreram, no país e no estado de São Paulo, antes e depois da criação das Escolas Modernas. Uma ocorrência primeira foi a Escola União Operária, fundada no Rio Grande do Sul em 1895, provavelmente originária da iniciativa dos ex-integrantes da Colônia Cecília, como indica Edgar Rodrigues, seguida da criação, também naquele estado, na cidade de Porto Alegre, de uma outra escola fundada em homenagem ao Eliseé Reclus, a Escola Eliseé Reclus, local que o militante anarquista teria visitado em sua passagem pelo Brasil. Em São Paulo, a Escola Liberária Germinal surgiu em 1903, e seguia o método da Escola Moderna de Barcelona. Na cidade de Santos, a União Operária dos Alfaiates teria fundado, em 1904, a Escola Sociedade internacional, e a Federação Operária, a Escola Noturna, em 1907. Há, ainda, o registro das chamadas Escolas Livres, como as de Campinas, fundada, em 1909, pela Liga Operária; a Escola da Liga Operária de Sorocaba, criada em 1911; a Escola da União Operária de Franca, fundada por Teófilo Ferreira, em 1912; e o
}

TrabalhoNecessário- www.uff.br/revistatrabalhonecessario: ano 16, №29/2018 
Pública do Estado para instalar e fazer funcionar o estabelecimento, o Comitê decidiu entregar a direção da Escola a uma pessoa identificada com a doutrina libertária e portadora das qualidades pedagógicas necessárias ao exercício pedagógico. A escolha recaiu no professor João Penteado, partidário da corrente kropotkiniana do anarquismo (comunista libertária) e admirador da obra de Francisco Ferrer Guardia, pedagogo espanhol fundador das Escolas Modernas de Barcelona (LUIZETTO, 1986; 1987).

João de Camargo Penteado nasceu em Jaú, interior do estado de São Paulo, em 04/08/1877, e faleceu, na capital, em 31/12/1965. Autodidata, iniciou a carreira de professor concursado no magistério municipal de Jaú, tendo lecionado, depois, em outras cidades do interior do estado. Nos anos 1900, ainda em Jaú, associou-se ao Centro Operário da cidade, tornando-se redator do jornal "O operário", "órgão das classes trabalhadoras", fundado provavelmente em 1905. É difícil afirmar em que época exatamente João Penteado teria entrado em contato com os escritos de Kropotkin, Reclus, Grave e outros comunistas libertários, cujos livros podem ser encontrados em sua biblioteca. Para Romani (2002), Penteado teria conhecido as propostas da educação libertária e a pedagogia de Ferrer em uma das conferências realizadas por Oreste Ristori em Jaú. De qualquer maneira, como assinala Luizetto (1986), seus textos publicados na imprensa operária ${ }^{9}$ revelam familiaridade com as ideias próprias daquela concepção do anarquismo. As pesquisas realizadas pelo grupo de estudo João Penteado revelam também as afinidades desse educador com as concepções do cristianismo anarquista de Tolstói (ACCIOLY e SILVA, D.; SANTOS, L., 2013, p. 200).

As Escolas Modernas de São Paulo foram fechadas em 1919, por ordem da Diretoria da Instrução Pública do Estado de São Paulo, após acidente provocado pela explosão de uma bomba no bairro do Brás, no qual perderam a

surgimento de uma Escola Moderna, em São Caetano, em 1919. Rodrigues (1992) menciona, ainda, a Escola Nova, fundada em 1912, no bairro da Mooca, em São Paulo, por Florentino de Carvalho, e a existência em 1920, também na capital, da Escola Joaquim Vicente. O levantamento existente sobre as escolas anarquistas e sua organização é bastante incompleto, fazendo-se urgente o necessário trabalho de mapeamento dessas instituições e a localização das fontes documentais a elas relacionadas, visando sua preservação e organização.

${ }^{9}$ João Penteado contribuía regularmente com a imprensa operária, escrevendo artigos em jornais anarquistas como "A Plebe", "A Lanterna", "A Rebelião", entre outros (Arquivo Edgar Leuenroth/Unicamp e Arquivo Escolar João Penteado, CME-FEUSP). A esse respeito, consultar Santos, Luciana 2007.

TrabalhoNecessário- www.uff.br/revistatrabalhonecessario: ano 16, №29/2018 
vida quatro militantes anarquistas, entre eles José Alves, diretor da Escola Moderna de São Caetano ${ }^{10}$.

No que se refere aos Ginásios Vocacionais, de acordo com os objetivos propostos, estamos trabalhando com documentos pertencentes a dois acervos: 0 do Centro de Documentação e Informação Científica "Professor Casimiro dos Reis Filho" - Cedic, da Pontifícia Universidade Católica de São Paulo, constituído nos anos 1990 por iniciativa de Maria Nilde Mascellani; e o do Centro de Memória da Educação - CME, da Faculdade de Educação da Universidade de São Paulo, organizado em 2009, a partir dos documentos doados por Silvana Mascelani, irmã de Maria Nilde, após a morte da educadora.

No final dos anos de 1950 e início da década seguinte, em um período de ampla discussão de ideias, propostas de desenvolvimento nacional e preocupação com a formação oferecida aos estudantes no então ensino secundário (médio), organizado em dois ciclos - o ginasial e o colegial - e marcado por uma formação dualista que cindia a formação geral e a preparação para o trabalho, um grupo de gestores públicos e educadores procuraram adequar o ensino secundário ao que consideravam como exigências de uma sociedade em transformação.

No ano de 1961, por meio da Lei 6.052, foram aprovadas as reformas do ensino industrial no Estado de São Paulo, que se anteciparam à promulgação da Lei de Diretrizes e Bases da Educação Nacional em 20 de dezembro do mesmo ano. A partir de uma brecha nesta lei estadual, educadores que questionavam a dualidade do ensino, conseguiram criar o Serviço de Ensino Vocacional - SEV e viabilizar uma nova concepção de educação. A partir da promulgação da Lei no

\footnotetext{
${ }^{10}$ Excerto do Relatório do Interior de São Paulo no ano de 1919, apresentado em anexo por Luizetto, 1984. Documentos manuscritos de João Penteado, 1919 (Arquivo João Penteado/CMEFEUSP). A respeito do episódio, consultar também Marques, A. s/d. As experiências das escolas libertárias, as de São Paulo e as organizadas por todo o país, sugerem que o movimento libertário alcançou mais densidade do que geralmente faz supor a história do anarquismo brasileiro, centrado nas greves e reivindicações trabalhistas. As iniciativas e os esforços empreendidos para promover a educação, sobretudo em sua forma escolar, indicam que segmentos expressivos de trabalhadores, ainda que de modo incipiente, organizaram-se vislumbrando alcançar mudanças profundas na sociedade. As iniciativas de cunho educacional agregaram tanto militantes imigrantes - como Orestes Ristori, Gigi Damiani, Adelino de Pinho, Florentino de Carvalho, e Neno Vasco - quanto militantes brasileiros - como Edgard Leuenroth, Octavio Brandão, João Penteado, José Oiticica, Rodolpho Felipe e Zeferino Oliva, entre outros. Destes, João Penteado, Adelino de Pinho e Florentino de Carvalho estiveram diretamente relacionados ao funcionamento de escolas libertárias, sobretudo em São Paulo (LUIZETTO, 1986; SANTOS, 2007).
}

TrabalhoNecessário- www.uff.br/revistatrabalhonecessario: ano 16, №29/2018 
4.024/61, a LDB de então, os ginásios vocacionais passaram a se respaldar na lei federal.

No início da década de 1960, surge o SEV e são implementados os três primeiros ginásios vocacionais nas cidades de São Paulo, Americana e Batatais. Ao todo foram criadas seis escolas estaduais, uma na capital e cinco no interior do Estado. Vivenciávamos, então, um dos momentos mais ricos e fecundos de nossa história, marcado por inúmeras iniciativas no campo social, político e cultural, entre as quais se destacavam as ações de jovens universitários, trabalhadores organizados e educadores comprometidos com a ampliação da escolaridade das classes populares. Nesta perspectiva de atuação engajada, voltada para a democratização das oportunidades educacionais, para a difusão, em espaços formais e não formais, da cultura e da educação para a população marginalizada, surge a proposta de formação humana e emancipatória elaborada pela professora Maria Nilde Mascellani e sua equipe.

A proposta nasce inicialmente em caráter experimental, com o intuito de construir escolas públicas diferenciadas, caracterizadas por nova concepção formativa, tanto no que diz respeito à renovação metodológica, quanto aos fundamentos que norteiam a construção da prática pedagógica. Com visão arrojada e projeto pedagógico consistente, a educadora Maria Nilde, coordenadora do SEV, e sua equipe, iniciaram a concretização da proposta escolhendo diferentes locais para a instalação das escolas. Um planejamento minucioso foi efetuado a partir de estudo sobre os moradores do local onde cada unidade se implantaria: havia interesse em diversificar a experiência educacional em comunidades diferentes, uma com característica mais cosmopolita, outra situada em região agrícola, outra em área industrial, e assim por diante, visando adequar a proposta de trabalho dos ginásios à realidade local.

Com essas orientações, o Ensino Vocacional passou, ao longo do tempo, a implementar programas de formação de professores para difundir a metodologia das escolas entre os licenciandos das universidades públicas, e a oferecer estágios a universitários, visando alcançar efeito multiplicador via propagação das experiências vivenciada. Pretendia-se, assim, expandir paulatinamente estas escolas em toda a rede pública paulista, ministrando sempre formação teórica articulada à prática por meio de programa desenvolvido em tempo integral, de quatro anos, que contemplasse as múltiplas dimensões da experiência humana.

TrabalhoNecessário- www.uff.br/revistatrabalhonecessario: ano 16, №29/2018 
Com esta concepção e abrangência também foram criados, em março de 1968, junto ao Ginásio Vocacional do Brooklin, na capital, o período noturno e o segundo ciclo do então ensino secundário, hoje correspondente ao ensino médio, ambos com programas fortemente voltados ao mundo do trabalho. Em 1969, a Sociedade de Pais e Mestres do Ginásio Vocacional de Rio Claro também reivindicou da Secretaria de Educação do Estado o período noturno, seguido pelos Ginásios Vocacionais de Rio Claro e Barretos. Importantes e únicas experiências de ensino integrado para jovens e adultos no país, tiveram - no entanto - duração efêmera, menos de dois anos.

Em 1964, ocorre o golpe civil/ militar e tem início o governo ditatorial que suprimiu as liberdades democráticas. Em 1968, com o Ato Institucional oㅜ 5, houve o recrudescimento do regime e várias ações discricionárias, com o aumento das perseguições políticas, cassações de mandato e de direitos políticos, prisões, inquéritos policiais militares, proibições de reuniões e de associações. Toda sorte de restrições foi aplicada aos opositores do governo. No campo da educação, as perseguições se voltaram, de início, aos que se dedicavam à educação popular e ao trabalho com jovens e adultos, estendendose em seguida aos professores universitários e aos docentes da educação básica, considerados subversivos pelo regime vigente.

Em um contexto de grande repressão e violência, mais precisamente no dia 12 de dezembro de 1969, as seis escolas e a sede do SEV foram invadidas por agentes da polícia federal e por militares e seus professores, funcionários e alunos detidos. Todos os setores das escolas e do SEV foram vasculhados e seus livros, textos de estudo, relatórios e material pedagógico apreendidos e levados por agentes policiais. A professora Maria Nilde Mascellani foi cassada e aposentada com base no Al-5, e a experiência vocacional, que já vinha sofrendo perseguições, será oficialmente extinta pelo Decreto $\mathrm{n}^{0} 52.460$, de 05 de junho de 1970. As escolas passaram, então, a seguir os padrões oficiais de ensino dominantes na rede estadual.

Conviveu-se, por muitos anos, com um hiato na história da educação brasileira: enquanto perdurou a ditadura civil militar, os protagonistas desta rica experiência sentiram-se ameaçados em sua integridade física; muitos documentos foram queimados e houve o silenciamento da memória do Ensino Vocacional. As fontes que restaram, guardadas na residência de professores,

TrabalhoNecessário- www.uff.br/revistatrabalhonecessario: ano 16, №29/2018 
coordenadores pedagógicos e diretores, prudentemente esquecidas em baús e gavetas, só puderam ser recuperadas e compiladas em alguns poucos acervos após o fim do regime militar.

O conjunto de documentos doados, que constitui o Arquivo Pessoal da profa. Maria Nilde corresponde à sua vida profissional nos períodos em que atuou como orientadora pedagógica nas duas classes experimentais instaladas no Instituto de Educação da cidade de Socorro; como educadora da Secretaria de Educação do Estado de São Paulo, participando da comissão especial de elaboração do anteprojeto de lei para a criação dos Ginásios Vocacionais do Estado de São Paulo; como coordenadora geral do Serviço de Ensino Vocacional (SEV), que funcionou entre os anos de 1962 a 1969. Constam, ainda, o processo de sua aposentadoria em 1969, por meio do Ato Institucional n. 5 (AI5), e manuscritos pessoais, reflexões reunidas em um diário (na forma de crônicas, cartas e poesias) que a própria autora nomeou de "Crônicas do Cárcere", escrito no período que esteve presa (no DOPS- Departamento de Ordem Política e Social). Fazem, também, parte deste Arquivo documentação relativa ao período em que prestou serviço para as Secretarias de Educação de São Paulo, Diadema e Rio Claro, e contribuiu na concepção de projetos em educação popular.

Neste momento em que fazemos a participação pública dos resultados parciais da pesquisa, toda a documentação já recebeu o necessário tratamento de higienização e acondicionamento, e passa agora pelo processo de análise para elaboração do plano de classificação. $O$ arquivo corresponde a 32 caixas com, aproximadamente, 900 documentos entre livros, periódicos, cartões postais, fitas $k 7 \mathrm{com}$ entrevistas realizadas com ex-alunos e ex-professores dos vocacionais, recortes de jornais, imagens e material didático produzido para trabalhadores, cópias de documentos oficiais de diferentes unidades dos Ginásios Vocacionais e do Serviço de Ensino Vocacional. É importante ressaltar que foram também localizados aproximadamente 800 documentos relacionados ao ensino vocacional, cedidos por ex-professoras e diretoras das escolas, distribuídos em diferentes arquivos que constituem o Acervo do Centro de Memória da Educação/FEUSP (MORAES; TAMBERLINI; ZAIA, 2012).

Na vasta documentação dos acervos do Cedic/ PUC de São Paulo e do CME - FEUSP encontram-se documentos pedagógicos, relatórios, legislação estadual, federal e documentos internos do SEV, textos produzidos por

TrabalhoNecessário- www.uff.br/revistatrabalhonecessario: ano 16, №29/2018 
professores e diretores, prestação de contas ao governo, registros das reuniões

de planejamento, dos encontros de orientadores educacionais, impressos de circulação interna, textos, programas e avaliações das mais diferentes disciplinas, objetivos que as escolas almejavam alcançar na formação do alunado, fichas de observação do aluno com registros do percurso escolar de cada um e áreas do conhecimento em que as crianças e jovens se destacavam, buscando descobrir a sua vocação, documentos do departamento de publicações, textos de autoria dos professores apresentados nos encontros nacionais da Sociedade Brasileira para o

Progresso da Ciência, atas das Associações e da Federação de Pais e Amigos dos Ginásios Vocacionais, além de teses e dissertações que versaram sobre estas escolas. Constam também, nestes acervos, os livros dos autores utilizados como referência nas concepções de homem que se pretendia formar nestas instituições, com destaque para as obras do socialista cristão Emmanuel Mounier.

Os acervos ainda contêm várias pastas com recortes de jornais e revistas da época, com os diferentes posicionamentos dos órgãos de imprensa sobre as escolas e suas práticas inovadoras. Há também ricas fontes iconográficas, além de inúmeras fotos presentes nos acervos das associações de ex-alunos das diferentes escolas, hoje digitalizadas e com acesso facilitado na internet.

O exame de várias fontes documentais torna possível resgatar, compreender e interpretar a construção e o sentido da pedagogia vocacional. Prisões, perseguições, exílios, conduziram à dispersão de pessoas e documentos desta experiência pedagógica que, por ter sido extinta abrupta e precocemente, não teve tempo de ser estudada e avaliada pelos seus realizadores.

O trabalho com fontes documentais escritas e iconográficas, aliadas à história oral, permite-nos preencher lacunas, romper com a tentativa de apagamento deste período histórico e trabalhar na perspectiva da totalidade da história, tal como concebida por Vilar (1992). Investigar a história de experiências significativas da educação pública no Brasil também nos permite despertar na juventude o interesse pela historiografia da educação, já que, como observa Hobsbawn (1995, p.13), grande parte da juventude atual cresce "numa espécie de presente contínuo sem qualquer relação orgânica com o passado público da época em que vivem".

TrabalhoNecessário- www.uff.br/revistatrabalhonecessario: ano 16, №29/2018 


\section{O Ensino Racionalista das Escolas Modernas e os Ginásios Vocacionais: notas introdutórias de um estudo comparativo das estratégias pedagógicas}

A proposta de resgatar as práticas educacionais operárias presentes no ensino racionalista desenvolvido nas Escolas libertárias, em particular na Escola Moderna n. 1 dirigida pelo educador anarquista João Penteado, e a dos Ginásios Vocacionais, instituição da rede estadual paulista dos anos 1960, visa possibilitar discussão mais ampla das formas de apropriação das estratégias pedagógicas que circulavam na sociedade brasileira, desde o século XIX, e irão assumir novos sentidos no movimento operário e sindical no início do século XX, e, mais tarde, entre os educadores democráticos e setores progressistas da Igreja Católica alinhados à Teologia da Libertação e ligados aos movimentos sociais populares no Brasil, os quais protagonizaram a organização dos Vocacionais. Nessa direção, pretende-se contribuir para restituir à história educacional do período a dimensão das disputas em torno de projetos pedagógicos diferenciados e a mobilização de dispositivos que serviram a uma pluralidade de propósitos distintos e/ou antagônicos (MORAES, GIGLIO, HILSDORF, 2008).

Nessa direção, o texto não propõe apresentar estudo detalhado comparativo das práticas pedagógicas dessas iniciativas educacionais. Interessa demarcar nas escolas em estudo a existência de algumas interfaces em suas práticas pedagógicas e nas concepções teóricas que as informam.

No que se refere às Escolas Modernas, é importante enfatizar que a imprensa anarquista e operária, nas duas primeiras décadas do século $X X$, assume forte dimensão educadora do operariado por meio da divulgação tanto dos ideais anarquistas quanto das teorias da educação racionalista, promovendo um campo de disputas em torno do modelo escolar operário recomendado pelos Congressos Operários Brasileiros e influenciando as experiências de educação escolar operárias a partir da pedagogia racionalista (MORAES, GIGLIO, HILSDORF, 2008). Além das notícias da imprensa anarquista e operária da época, a escola mantinha dois periódicos, por meio dos quais mantinha comunicação permanente com os alunos e seus pais: $O$ Início - publicação de propaganda e órgão dos alunos da escola moderna, e o Boletim da Escola Moderna - publicação coordenada pelo diretor João Penteado. 
Como foi observado anteriormente, os documentos indicam que a pedagogia libertária assimilou os pressupostos da educação integral, defendidos por Bakunin, Kropotkin e sistematizados por Paul Robin no Orfanato de Cempuis e Sebastien Faure, em La Rouche, ambos na França, e do ensino racional, organizado e difundido por Ferrer na Escola Moderna de Barcelona (1901). O Programa de Ensino Integral foi elaborado por Paul Robin para ser apresentado nos Congressos da Internacional de Trabalhadores em Lausane (1867) e em Bruxelas (1868), sendo, finalmente, incorporado ao Programa Educacional do Comitê para o Ensino Anarquista, de 1882, após o encerramento da Internacional (1876) (LUIZETTO, 1986; MORAES; CALSAVARA; MARTINS, 2013).

A concepção de educação integral e igualitária, assumida consensualmente como exigência prioritária pela Primeira Internacional, por Bakunin e Marx, e pelas tendências que ambos representavam, opunha-se à existência de dois tipos de ensino - um "aprimorado", reservado aos burgueses, e outro "simplificado", destinado aos trabalhadores, que expressa a dominação de classe.

A essa concepção, Paul Robin irá enfatizar, na apreensão de seu significado, a existência de três dimensões necessariamente integradas: física, moral e intelectual. Francisco Ferrer y Guardia, na direção das formulações de Robin, defende a educação integral para possibilitar "o pleno desenvolvimento de todas as capacidades do indivíduo", "integrando o trabalho manual e o intelectual" (FERRER y GUARDIA, 1978). Nesta perspectiva, propõe a utilização de métodos ativos, a coeducação social e de sexo, e a integração da escola com seu entorno físico e social (MORAES et al., 2011).

Dessa maneira, a pedagogia racionalista vai formular, da perspectiva do movimento libertário, um modelo próprio de educação escolar que leva em conta os três elementos que marcam o quadro do debate internacional no período e que pode ser aplicado por todos (comunistas, anarquistas, socialistas), pois tem na escola um instrumento da revolução: a educação das mulheres, o ensino científico e racional e a educação leiga (MORAES, GIGLIO, HILSDORF, 2008).

É possível afirmar que tais concepções compõem uma perspectiva de renovação da sociedade, "de aposta na educação escolar como modelo civilizatório, e não mais nas formas não escolares de educação tais como a família, a igreja, as corporações de ofícios". Ou seja, "a partir desse ideário

TrabalhoNecessário- www.uff.br/revistatrabalhonecessario: ano 16, №29/2018 
anarquista os comunistas libertários irão negar o estado como organizador do sistema escolar de educação, mas não irão rejeitar a ideia da forma escolar" (idem, p.7).

As Escolas Modernas de São Paulo aplicaram em suas práticas cotidianas os princípios do ensino racionalista e da pedagogia anarquista. A documentação existente, os jornais escolares em particular, permite conhecer a organização curricular, os métodos de ensino e compêndios utilizados.

De acordo com notícia publicada em A Lanterna, $(05 / 09 / 1914)^{11}$, na Escola Moderna "o ensino deve ser integral, exercitando o aluno progressivamente em todos os conhecimentos intelectuais e físicos", propondo-se "a fazer da criança um homem livre e completo, que sabe por que estudou, por que refletiu, por que analisou, por que fez a si mesmo uma consciência própria". A concepção e importância do trabalho no processo de ensino das escolas dirigidas por João Penteado manifestam-se nos aspectos organizacionais e administrativos das instituições e em suas variadas dimensões/atividades pedagógicas - público alvo, corpo docente, cursos ofertados, conteúdos e métodos de ensino (MORAES; CALSAVARA; MARTINS, 2013, p. 152-154). No anúncio publicado em A Plebe, lê-se que a instituição pretendia proporcionar:

\footnotetext{
Ensino teórico e prático, segundo os métodos da pedagogia moderna, com os quais se ministra aos alunos uma instrução que os habilita para o início das atividades intelectuais e profissionais, assim como uma educação moral baseada no racionalismo científico (A Plebe, 1917).
}

Na Escola Moderna n. 1, criada em 1912, havia uma aula diurna, das 11 às 16 horas (aos sábados, das 11 às 13 horas, após o retorno do "passeio campestre") e outra noturna, de segunda à sexta-feira, das 19 às 21 horas. A grade curricular compreendia as seguintes matérias: leitura, caligrafia, português, aritmética, geografia, história do Brasil, noções de história e princípios de ciências naturais $^{12}$. A Escola Moderna N.․ 2, criada provavelmente em 1913, mantinha apenas uma aula diurna, das 12 às 16 horas. A grade curricular estava constituída das seguintes matérias: leitura, caligrafia, gramática, aritmética, geometria, geografia, botânica, zoologia, mineralogia, física, química, fisiologia,

\footnotetext{
11. A Lanterna, jornal anticlerical, estava sob a direção de Edgar Leuenroth, na época.

${ }_{12}$ Peres, 2004, p. 122; Germinal! 13/7/1913; A Lanterna, 22/08/1914; A Lanterna, 15/04/1916.
}

TrabalhoNecessário- www.uff.br/revistatrabalhonecessario: ano 16, №29/2018 
história, desenho, etc. Em seus comunicados, o Comitê Pró - Escola Moderna comunicava às famílias, as grandes linhas que deveriam orientar a oferta das disciplinas nestas escolas: "Educação artística intelectual e moral; conhecimento de tudo quanto nos rodeia; conhecimento das ciências e das artes; sentimento do belo, do verdadeiro e do real; desenvolvimento e compreensão sem esforço e por iniciativa própria" (MATE; SANTOS; PERES; ZAIS, 2013, p. 63-64).

Atividades extra-classes eram valorizadas como complementares: as excursões campestres com objetivos "pedagógicos" e os passeios na cidade (origem de temas para os exercícios escolares cotidianos), as visitas aos museus, exposições e monumentos considerados importantes à história do país ou da humanidade. Além dos jogos e das práticas esportivas, outras práticas pedagógicas eram vivenciadas na escola: o grêmio estudantil, o cine-educativo, o teatro-educativo e a biblioteca escolar. Tais instrumentos eram destinados aos alunos, mas permitia-se a participação de outras pessoas, como ex-alunos e os moradores do bairro que não eram alunos. A relação da escola com a comunidade, sua "face pública", manifestava-se nos exames finais abertos ao público, nos festivais de encerramento das aulas, entrega de diplomas e prêmios e nas exposições de trabalhos de alunos; e também nas festas de colação de grau, nos álbuns atividades de formatura e nos convescotes de despedida da vida escolar (Idem, p. 66).

Guardadas as suas especificidades, tanto históricas quanto filosóficas, a proposta dos Ginásios Vocacionais apresenta convergências significativas com a das escolas anarquistas no que se refere a concepções e práticas de ensino. $O$ Vocacional constitui experiência única na história da educação pública no país: questionava a formação dual realizada na escola média, a separação entre a formação intelectual, de caráter acadêmico, voltada às classes dirigentes, e a formação para o trabalho, dirigida à população de baixa renda, bem como buscava oferecer ao seu alunado uma educação de qualidade. Valorizando o trabalho, concebido como importante dimensão da formação humana, não aceitava a divisão entre pensar e fazer. A sua proposta pedagógica, marcada por uma concepção ampla de educação, inspirada no socialismo cristão de Emmanuel Mounier, em experiências educacionais como a realizada na Escola Bibiana, organizada pelo padre Don Lorenzo Milani para os filhos dos camponeses de Bibiana, Itália, e interagindo com o ideário emancipador presente

TrabalhoNecessário- www.uff.br/revistatrabalhonecessario: ano 16, №29/2018 
nas discussões da época, entre eles o de Paulo Freire, logrou edificar uma das propostas mais completas realizadas na escola pública de nível médio em nosso país. Mais tarde, como Maria Nilde Mascelani irá explicitar na tese de doutorado em que resgata a história da implementação dos Ginásios Vocacionais, novas aproximações teóricas haviam sido feitas no decorrer da vivência cotidiana dos desafios educacionais, com a inclusão de autores marxianos, em particular, de Gramsci, e do próprio Marx (MASCELANI, 2010; MORAES; TAMBERLINI; ZAIA, 2012).

Os Vocacionais se valiam dos métodos ativos, constitutivos do ensino renovado: tratava-se de proposta de cunho transformador, que buscava capacitar o aluno para atuar na comunidade em que vivia. Na direção da pedagogia libertária, concebendo a formação geral integrada à formação para o trabalho, estas escolas diferenciadas não dissociavam educação e cultura, nem tampouco educação e trabalho. De acordo com o local em que a escola estava localizada, aulas das disciplinas de caráter teórico eram ministradas articuladamente a conteúdos das áreas técnicas. A elaboração do currículo de cada unidade era precedida da realização de uma pesquisa de comunidade, cujo objetivo consistia em investigar as várias características da localidade onde a escola estava localizada: economia local, escolaridade da população, perfil dos moradores, nível cultural, nível de aspiração em relação à formação das crianças, perfil do alunado, etc. O ginásio mantinha forte interação com a comunidade e o planejamento pedagógico escolar levava em conta as suas expectativas e demandas, com o propósito de também melhorar o nível cultural da população local, tornando-se assim um polo irradiador de cultura.

Para formar o aluno crítico, atuante, participativo e engajado, era de capital importância a adoção de uma metodologia que contribuísse para o desenvolvimento destas atitudes. E, assim como na Escola Moderna, o recurso ao estudo do meio era a principal técnica pedagógica utilizada nos Vocacionais, ao lado do estudo dirigido, do trabalho em grupo, dos métodos ativos ligados à coordenação das disciplinas e do planejamento geral. A proximidade com a realidade da comunidade local e o estudo de "atualidades" tinham o intuito de facilitar a compreensão inicial da sociedade e do processo histórico, e despertar no aluno o compromisso social e a perspectiva de uma participação cidadã. A concepção de que a educação transcende os muros da escola, aliada ao

TrabalhoNecessário- www.uff.br/revistatrabalhonecessario: ano 16, №29/2018 
profundo enraizamento na vida da comunidade local, orientava a valorização das vivências e experiências dos alunos, já que esta pedagogia concebia o ser humano situado no tempo e no espaço, compreendendo que o aluno iria elaborar o seu conhecimento a partir de suas vivências, para extrair de situações concretas a construção de formas de agir, sentir e organizar conceitos.

A proposta pedagógica dos Ginásios Vocacionais Noturnos, assentada na mesma filosofia que orientou os Ginásios Vocacionais de tempo integral, seguia orientações comuns à pedagogia libertária na sua relação com a cidade e o entorno escolar. Destinada a jovens e adultos trabalhadores que retomavam os estudos escolares, seu planejamento foi realizado por meio de pesquisa diagnóstica do meio social em que se organizava. Coerentemente com o conceito de currículo vigente nas escolas vocacionais diurnas, definido "como trajetória de experiências vividas pelos alunos e orientadas por objetivos definidos pelos educadores", o planejamento curricular do noturno foi elaborado a partir "das necessidades dos jovens e adultos", e estabelecia "como linhas orientadoras o debate sobre o trabalho e suas implicações econômicas, políticas e culturais" (MASCELANI, 2010, p. 141).

O core-curriculum, "ideia central que viabiliza os demais componentes curriculares", foi assim formulado: "o trabalho humano como instrumento de transformação da natureza, da sociedade e do próprio homem". Segundo Maria Nilde (2010, p. 141):

A proposta pedagógica foi pensada como um campo rico de experiências, de promoção humana e social e de formação da consciência crítica, condição básica para o homem intervir na realidade de modo pensado e planejado. A proposta coloca o coletivo acima do individual, a comunicação grupal e intergrupal como meio de sociabilidade e de coesão social, a intervenção como prática de cidadania, situações voltadas permanentemente sobre a realidade econômica, política e cultural (NILDE, 2010, p.141.

Em todos os Ginásios Vocacionais Noturnos as primeiras abordagens dos professores e orientadores caminharam no sentido de resgatar a experiência e o conhecimento trazido pelos alunos trabalhadores. A partir daí, articulava-se às metodologias e aos conteúdos de cada área. O currículo integrado, além das áreas de língua portuguesa, matemática, estudos sociais (história, geografia e

TrabalhoNecessário- www.uff.br/revistatrabalhonecessario: ano 16, №29/2018 
antropologia), ciências físicas e biológicas, inglês, era constituído pelas de educação física, artes industriais, práticas comerciais e/ou agrícolas, educação musical, artes plásticas e economia doméstica.

A prática pedagógica foi se estruturando em dois momentos básicos complementares: o trabalho no bairro e o estudo no Ginásio. O bairro consistia o espaço do trabalho de campo - do estudo do meio e da ação comunitária, - e o Ginásio, o lugar do estudo, da análise da realidade e do planejamento das ações a serem implementadas no bairro ou na escola. Nessa trajetória, os alunos contavam não só com os seus professores, mas também com a participação de "colaboradores do Ensino Vocacional", os pais e professores das mais diversas áreas profissionais. Segundo informações de Mascelani (2010, p.149):

\footnotetext{
O trabalho no bairro atingiu também mulheres, jovens e crianças. Foram montados projetos especiais para cada segmento. As alunas do noturno tiveram papel decisivo entre as mulheres. No primeiro ano de trabalho foram organizados vários grupos de trabalhadores por bairros. (MASCELANI, 2010, P.149).
}

Cabe destacar que nos finais de semana ocorriam, nas escolas, muitas atividades culturais como, por exemplo, a organização de uma galeria de arte no Ginásio Estadual Vocacional Cândido Portinari, de Batatais, pelos seus alunos, pais e moradores da cidade. A família do pintor, cujo nome foi utilizado para batizar a escola, emprestou algumas obras do artista para a realização da mostra no colégio. $O$ dramaturgo Jorge Andrade também ministrou aulas de teatro para os alunos do Ginásio Vocacional Embaixador Macedo Soares, em Barretos, onde professor e estudantes exibiam peças de teatro nos finais de semana para a comunidade local.

\section{Considerações finais}

Em disputa com os projetos da elite dominante, mesmo enfrentando diversos obstáculos e perseguições políticas, muitas foram as contribuições das Escolas Modernas e dos Ginásios Vocacionais, que, em sua curta existência, inovaram a educação brasileira implementando e difundindo concepções e práticas pedagógicas valorizadas ainda hoje no campo da educação democrática. 
Propondo-se a viabilizar a apropriação, pela classe trabalhadora, do saber socialmente constituído e distanciando-se das escolas de ensino médio profissional, organizadas segundo o modelo da dualidade escolar e que com poucas variações marcaram a história da educação para os trabalhadores no Brasil, essas experiências nunca formaram para o mercado. Ao se proporem a formar os educandos pelo trabalho e para o trabalho - compreendido não só como valor de troca, mas também como valor de uso, atividade vital do homem -, desenvolveram um tipo de formação humana e emancipatória, destinada a trabalhadores jovens e adultos, vistos como seres integrais que, por meio da educação e do trabalho, poderiam construir sua autonomia - individual e coletiva frente aos poderes econômicos e políticos.

Como expressão concreta dos laços que unem no tempo tais iniciativas emancipatórias de educação, encontramos entre os protagonistas do ensino Vocacional um antigo professor proveniente da escola libertária de João Penteado, o professor Luiz Contier. No início dos anos 1960, ao lado da profa. Maria Nilde Mascelani, fez parte da "equipe coesa de reformadores do ensino" (TAMBERLINI, 2001, p. 47) que esteve no Liceu de Sèvres, instituição implementada por educadores participantes da resistência francesa ao nazismo com o objetivo de formar a nova geração para a democracia (idem, p. 47).

O Liceu, moderno e bem equipado, aplicava, entre outras inovações, os "métodos ativos" que visavam adaptar a pedagogia à democratização do ensino. Segundo Tamberlini (2001, p. 46-7), os métodos ativos abrangiam o "aprender também fazendo", os desenhos e trabalhos manuais, trabalho em equipe, o estudo do meio humano natural e social, e manifestava-se contra a dualidade no ensino, tendo por pressuposto a democratização do ensino médio, que não mais deveria estar dirigido aos meios sociais privilegiados.

A visão da escola como centro irradiador de transformação social, a proposta de currículo integrado, o trabalho como princípio educativo e os recursos pedagógicos do estudo do meio na aproximação entre escola e cidade (polis), a participação coletiva, o trabalho em equipe, a autogestão e a autoavaliação conformam o ensino destas escolas em sua tentativa de construção da escola unitária - proposta que, como pretendemos indicar, faz parte das lutas do movimento operário desde o século XIX.

TrabalhoNecessário- www.uff.br/revistatrabalhonecessario: ano 16, №29/2018 
Mas, nesse processo, além de interagir com o ideário emancipador presente nas discussões da época, como Mounier e Paulo Freire, por exemplo, há ainda a existência de interfaces entre as propostas do Ensino Vocacional e as concepções do movimento escolanovista que impregnaram fortemente o debate educacional no Brasil, nos anos 1930, e lançaram as bases para os temas discutidos nas décadas de 1950 e 1960 e os "métodos ativos" do Liceu de Sèvres. Pode-se mesmo supor também a existência de pontos de contato entre as Escolas Anarquistas e as concepções da Escola Nova, em particular na vertente de John Dewey, cujo pensamento já se encontrava difundido nos EUA e em diversos países europeus no início do século XX, inclusive na URSS no seu período revolucionário ${ }^{13}$. Mesmo levando em conta as controvérsias entre os educadores liberais e a esquerda em relação à escola ativa, é interessante demarcar, por exemplo, a supressão por Stalin das metodologias dos chamados "Pioneiros do ativismo espontaneísta", como Anatoly Lunacharsky, Pavel Blonsky, Moisey Pistrak, Nadezhda Krupskaya (JOVINE, 1997, apud DORE, R., 2014, p. 305).

A esse respeito, o educador libertário João Penteado que dirigiu a Escola Moderna $\mathrm{n} 1$, também parece ter se preocupado com as ideias sobre educação difundidas no período e agregou à sua biblioteca obras como "Como pensamos- $\mathrm{A}$ Pedagogia Moderna", de John Dewey (MATE, SANTOS, CALSAVARA, 2013, p.95). Da mesma maneira, seria possível indagar como hipótese - no âmbito da circulação das ideias - o movimento inverso: partindo-se da heterogeneidade existente nas formulações teóricas do ensino "renovado" é possível supor a apropriação também diferenciada, pelas suas diferentes vertentes, das concepções pedagógicas de correntes pedagógicas originárias do movimento

\footnotetext{
${ }^{13} \mathrm{~A}$ esse respeito, é interessante mencionar, conforme indicam as pesquisas de Sheila Fitzpatrick (1970, p.29-30), que a seletiva biblioteca sobre "a escola do trabalho" publicada pela Filial de Petrogrado da Narkompros (Comissiariado do Povo para a Educação), na União Soviética, em 1918, incluía August Lay, John Dewey, Kerchensteiner, Ferriere, Montessori e a educadora russa contemporânea K.N. Ventsel. Ao mesmo tempo, a filial de Petrogrado do sindicato de professores não bolcheviques - (VOUS) - que não era próximo do Narkompros- publicou quase idêntica bibliografia sobre o mesmo assunto, com a adição de trabalhos de Tolstoy, do tolstoyano S.T. Shatsky, de Kropotkin e Ushinsky. Krupskaya era amiga do tolstoyano Gorbunov-Posadov e publicou artigos dele em seu jornal Svobdnoe vospitanie antes da revolução. A escola experimental de Shatsky continuou sob o patrocínio do Narkompros, que se estendeu também à escola tolstoyana em Yasnaya Polyana, administrada pela filha de Tolstoy. Krupskaya recomendou a publicação do trabalho de Kropotkin sobre educação.
} 
operário internacional e de correntes políticas anarquistas e socialistas, antagônicas ao Estado capitalista.

Em resumo: foram aqui apresentadas, em recorte parcial e inicial, as estratégias educativas anarquistas e as do Ensino Vocacional com o objetivo de apontar a relevância do conjunto dessas experiências e indicar relações de continuidade entre elas como formas escolares concorrentes àquelas que predominaram na chamada "escola republicana" (MORAES, GIGLIO, HILSDORF, 2008), definida pelas políticas governamentais de educação no Brasil. Essas e outras hipóteses estão sendo problematizadas no decorrer da pesquisa em desenvolvimento.

\section{Referências}

ACCIOY e SILVA, D.; SANTOS, L. Trajetória e produção literária de João Penteado a partir de seu arquivo pessoal. In: MORAES, C.S.V. (org.) Educação libertária no Brasil. Acervo João Penteado: Inventário de Fontes. São Paulo: FapUnifesp; Edusp, 2013.

CHAUI, M. Apontamentos para uma crítica da Ação Integralista Brasileira. In: Chauí, M. e Franco, M. S. Ideologia e mobilização popular. Rio de Janeiro: Cedec/Paz e Terra, 1978, p.19-30.

DORE, Rosemary. Afinal, o que significa o trabalho como princípio educativo em Gramsci? In: Educação e Trabalho. Cadernos CEDES, Campinas, v.34, n.94, p. 297-316, 2014.

FERRER GUARDIA, F. La escuela moderna. Barcelona: Tusquets Editor,1978.

FITZPATRICK, Sheila. The commissariat of enlightenment. Soviet Organization of Education and the Arts under Lunacharsky. Cambridge: Cambridge at the University Press, 1970.

FOOT HARDMAN, F. Nem pátria nem patrão. Vida operária e cultura anarquista no Brasil. São Paulo: Brasiliense, 1983.

GALLO, S. Educação Anarquista. Piracicaba: Unimep, 1995.

GIGLIO, Célia Maria Benedicto. Voz do trabalhador: sementes para uma nova sociedade. 1995. 177f. Dissertação (Mestrado em Educação) - FEUSP. São Paulo.

HOBSBAWN, Eric. Era dos extremos. O breve século XX - 1914-1991. São Paulo: Cia. Das Letras, 1995. 
LUIZETTO, F. Presença do Anarquismo no Brasil. Um estudo dos Episódios Literário e Educacional - 1900/1920. 1984. Tese - UFSCAR. São Carlos.

. O movimento anarquista em São Paulo: a experiência da Escola Moderna n.1(1912-1919). In: Educação e Sociedade, Revista do CEDES/ Unicamp, Ano VIII, n. 24, agosto, p. 18 - 47. São Paulo: Cortez, 1986.

. As utopias anarquistas. São Paulo: Brasiliense, 1987.

MARQUES, Antonio José. Escola Moderna de São Caetano, mimeo. S/d, 13 p.

MASCELLANI, Maria Nilde. Uma pedagogia para o trabalhador. São Paulo: IIEP/CME-FEUSP, 2010.

MATE; SANTOS; PERES; ZAIA. Práticas Escolares, Práticas Sociais. In: MORAES, C.S.V. (org.) Educação libertária no Brasil. Acervo João Penteado: Inventário de Fontes. São Paulo: Fap-Unifesp; Edusp, 2013.

MORAES; TAMBERLINI; ZAIA. Os Ginásios Vocacionais do Estado de São Paulo. Reconstruindo a História por meio de fontes primárias e secundárias que se complementam. Anais do Congresso Luso Brasileiro de História da Educação, Lisboa: 2012.

MORAES; GIGLIO; HILSDORF. Estratégias educativas anarquistas no Brasil. Eixo 7 - Políticas Educativas e Cidadania. Comunicação Coordenada - Trabalho, educação e luta social: memória e história de projetos e estratégias pedagógicas desenvolvidas por trabalhadores e para trabalhadores. Porto: Congresso Luso Brasileiro de História da Educação. Mimeo., 2008.

MORAES; CALSAVARA; MARTINS. O Ensino Libertário e a relação trabalho e educação: Algumas reflexões. In. MORAES, C.S.V. (org.) Educação libertária no Brasil. Acervo João Penteado: Inventário de Fontes. São Paulo: Fap-Unifesp; Edusp, 2013.

MORAES, Carmen S. V. et al. Inventário de fontes das escolas dirigidas pelo educador anarquista João Penteado (1912-1961): dimensão pedagógica e contribuição para a história da relação trabalho e educação no Brasil. Revista Brasileira de História da Educação, v. 11, n. 1 (25), p. 117-141, jan.-abr. 2011.

MORAES, CS V. (2006). O Ideário Republicano e a Educação. Uma contribuição à História das Instituições. Campinas-SP: Mercado de Letras/FAPESP.

RODRIGUES, E. O anarquismo na escola, no teatro, na poesia. Rio de Janeiro: Achiamé, 1992.

ROMANI, C. Oreste Ristori: uma aventura anarquista. São Paulo: AnnablummeFapesp, 2002. 
SANTOS, Luciana Elisa dos. A trajetória anarquista do educador João Penteado: leituras sobre Educação, Cultura e Sociedade. Dissertação de Mestrado, São Paulo, FEUSP, 2007.

TAMBERLINI, A.M.B. Os Ginásios Vocacionais: a dimensão política de um projeto pedagógico transformador. S. Paulo: Annablume/Fapesp, 2001.

VILAR, P. Pensar la Historia. Cidade do México: Instituto Mora, 1992.

Recebido em: 05 de novembro de 2017.

Aprovado em: 22 de fevereiro de 2018.

Publicado em: 13 de junho de 2018. 